\title{
Myocardial Infarction: Perspectives on Cardiac Regeneration and Cardiac Remote Conditioning Interventions to Limit Cellular Injury
}

\author{
John G. Kingma \\ Laval University, Québec, QC, Canada \\ Email: john.kingma@fmed.ulaval.ca
}

How to cite this paper: Kingma, J.G. (2020) Myocardial Infarction: Perspectives on Cardiac Regeneration and Cardiac Remote Conditioning Interventions to Limit Cellular Injury. World Journal of Cardiovascular Diseases, 10, 188-207. https://doi.org/10.4236/wjcd.2020.104019

Received: March 13, 2020

Accepted: April 19, 2020

Published: April 22, 2020

Copyright $\odot 2020$ by author(s) and Scientific Research Publishing Inc. This work is licensed under the Creative Commons Attribution International License (CC BY 4.0).

http://creativecommons.org/licenses/by/4.0/

\section{(c) (i) Open Access}

\begin{abstract}
Acute myocardial infarction initiates a cascade of events including loss of protein homeostasis and chronic inflammation that affect overall cellular repair and senescence. This contributes to loss of cardiomyocytes and consequent formation of fibrotic scar. In certain vertebrate species, the heart can completely self-repair or regenerate after myocardial injury; however, this does not appear to be the case for humans. Despite this limitation, studies using novel non-pharmacologic interventions designed to protect against ischemic damage and to improve patient outcomes are ongoing. Remote ischemic conditioning stratagems are used to attenuate ischemia-reperfusion injury in clinical and animal studies; endogenous protective factors that stimulate complex signal transduction pathways are deemed responsible. Some of these factors could conceivably act in concert with those involved in regulating cardiovascular regeneration. Numerous studies have focused on cardiac regenerative interventions using stem-cell based therapies and transplantation of cardiomyocyte (or other cell types) or biocompatible matrices. This review discusses recent progress of pre-clinical and clinical translational studies for cardiac regeneration. In addition, we submit that interventions using cellular adjunctive therapies combined with remote ischemic conditioning may prove to be of interest in the battle to find novel strategies for protection against cardiac injury.
\end{abstract}

\section{Keywords}

Cardiac Injury, Cardiac Regeneration, Myocardial Infarction, Remote Ischemic Conditioning

\section{Introduction}

Ischemic heart disease is a leading cause of mortality [1] [2]. Cardiac injury 
triggered by acute myocardial infarction results in rapid and significant loss of cardiomyocytes [3]. The adult human heart is limited in its capacity to regenerate, or to self-repair; [4] this is in contrast to other species (neonatal mice and swine, zebrafish, etc.) that are able to repopulate ischemic myocardium with minimal scar formation [5] [6].

The gold standard of treatment to limit myocardial injury is reperfusion of the infarct-related coronary artery using percutaneous coronary interventions [7]. On the other hand, reperfusion may exacerbate cellular injury that is manifest as myocardial stunning, coronary artery no-reflow, ventricular arrhythmias and cardiomyocyte necrosis, i.e. lethal reperfusion injury [8] [9].

Even though reperfusion is effective in patients, other strategies to regenerate damaged myocardium include transplantation of stem cells or cardiomyocytes, e.g. bone marrow-derived cells, resident cardiac cells, skeletal myoblasts, etc. to the ischemic zone and induction of cardiomyocyte proliferation [10]. Replacement of cardiomyocytes in adult humans could occur through mitotic division [11] [12]; however, the proliferative capacity of these cells remains unclear [4] [13].

Ischemic conditioning, e.g. preconditioning, postconditioning, preconditioning, remote conditioning, etc., the heart with repetitive episodes of non-lethal occlusion-reperfusion stimulates cellular protection pathways in animals and humans and protects myocardium and coronary vessels against injury [14] [15]. A plethora of animal and human studies examining the effects of ischemic conditioning on organ protection with different conditioning strategies has been published since it was initially reported in 1986; the reader is referred to several recent reviews that have addressed this topic [15] [16] [17].

This review discusses relevant translational studies with regard to cardiac regeneration as well as the potential influence of remote cardiac conditioning on ischemic injury. The literature search used MEDLINE and PubMed and was combined with a free search; keywords included angiogenesis, cardiac conditioning, cardiac regeneration, cardiomyocyte proliferation, cardioprotection, myocardial cell injury and stem cells.

\section{Physiopathology of Cell Death and Myocardial Remodeling}

An abrupt and total interruption of blood flow through an epicardial coronary artery leads to myocardial necrosis if reperfusion of blood to the ischemic bed is not rapidly restored. After onset of ischemia, a highly regulated process is activated to re-establish tissue architecture and morphology; the time to cell death varies among species. Cardiac cellular injury is characterized by marked swelling, development of contraction bands, mitochondrial calcification and membrane disruption [18]. It is often classified as reversible (reperfusion instituted within 15 minutes of acute coronary occlusion) or irreversible (failure to survive when environment is restored) and follows a transmural gradient from the inner to outer layers of the ventricular wall [7]. Various forms of reperfusion injury 
are described in the scientific literature; myocardial stunning, i.e. viable cardiomyocytes that exhibit prolonged post-ischemic contractile dysfunction even after reperfusion, and myocardial hibernation, i.e. viable, but chronically contractile dysfunctional cardiomyocytes. While the pathogenesis of cell death in non-cardiac cells is less considered in most studies, it is clear that vascular endothelial and smooth muscle cells along with nervous system components within the ischemic zone are negatively affected by coronary occlusion; this contributes significantly to overall loss of cardiac contractile function and limits recovery potential. Loss of these myocardial components probably renders the affected tissue non-salvageable for a number of reasons including no-reflow, or disrupted electrical conduction, etc. Timely reperfusion of the infarct-related artery by various clinical strategies (just enumerate them as reperfusion therapy which may be pharmacological, primary percutaneous coronary intervention, primary PCI, urgent coronary artery bypass graft, appears to limit overall myocardial damage; however, reperfusion itself may exacerbate injury via apoptosis or autophagy [19].

While patient survival after ischemia has markedly improved over the last forty years, the prevalence of chronic heart failure due, in part, to remodeling of the damaged left ventricle has also increased [20] [21]. Cardiac repair is a complex, tightly regulated process between innate and immune systems [22] that includes inflammation and infiltration of the infarct area by immune cell subtypes (neutrophils, monocytes, etc.), proliferation of myofibroblasts that deposit collagen required for scar formation, and maturation of scar tissue.

During evolving necrosis, pro-inflammatory cytokines released from cardiomyocytes promote recruitment of circulating inflammatory cells. Signals that stimulate upregulation of cellular adhesion molecules facilitate leukocyte adhesion, endothelial rolling and extravasation into damaged myocardium [21] [23]. Macrophages, which compose almost 10 percent of the non-cardiomyocyte population in the heart, are major constituents of post-ischemic cardiac repair; [24] neutrophils, which first infiltrate infarcted myocardium, phagocytize cellular debris, release proteolytic enzymes and generate reactive oxygen species that degrade extracellular matrix and initiate wound healing [25]. However, neutrophils also exacerbate cellular damage by microvessel plugging and release of cytotoxic compounds [26] [27]. The disproportionate accumulation of neutrophils could impede the transition from inflammatory to proliferative phase of cardiac repair. On the other hand, use of pharmacologic stratagems to limit inflammatory cell access to infarcted myocardium may not be ideal because it could constrain infarct healing and promote adverse myocardial remodeling [28] [29]. In addition, the complement cascade, which is part of the innate immune system, has been implicated in tissue regeneration; [23] inhibition of C5aR1, a complement receptor, increases scar size and attenuates proliferation of cardiomyocytes [30].

Once degradation and digestion of irreversibly injured cardiomyocytes, and other cell types, is complete, cardiac repair is initiated by accumulation of myo- 
fibroblasts, angiogenesis and deposition of collagen [31]. Inflammation and angiogenesis are inter-related: [32] release of vascular endothelial growth factor and other pro-angiogenesis or pro-survival factors within or near the infarct area stimulates maturation of nascent vessels but the precise mechanisms involved are not established.

Leukocyte infiltration is an important facilitator of healing that commences within the first week after reperfusion to the ischemic bed. At this time, a cascade of anti-inflammatory and pro-fibrotic mediators is released to permit the proliferation of fibroblasts that are required for development of a collagen-rich scar [33] [34]. Fibroblast expansion and conversion to a synthetic myofibroblast phenotype are central to the release of anti-inflammatory and pro-angiogenic factors that are involved in formation of granulation tissue; this is also a key component of the proliferative phase [35]. While their source is unclear, myofibroblasts (characterized on the basis of $\alpha$-smooth muscle actin expression) may arise from resident fibroblasts or circulating bone progenitor cells; [36] [37] regardless, these cell types promote synthesis of extracellular matrix proteins, i.e. collagen, fibrin, fibronectin, etc., that contribute to scar formation [38] [39]. Extracellular matrix changes require induction of matricellular proteins, e.g. thrombospondins, tenascins, osteopontin, etc., which modulate protease and growth factor activity during transition to scar formation.

In the heart, the extracellular matrix comprises basement membrane, interstitial matrix and extracellular fluid; proteoglycans, glycoproteins, cell-matrix interaction proteins and collagen are major structural components [40]. Inflammatory cells migrate within the extracellular matrix in response to stress and injury. Maturation comprises several steps including translation and post-translation (hydroxylation and glycosylation) of procollagen chains; collagen being the principle structural component of the extracellular matrix. Increased collagen cross-linking is associated with adverse remodeling, higher ventricular filling pressure and poor clinical outcome [41] [42]. Matricellular protein expression allows localization of inflammatory and fibrotic responses at or near the infarct border zone (existence of an infarct border zone has been debated elsewhere [43] [44]).

Extracellular matrix stiffness contributes to efficacy of post-infarction heart regeneration. In the mammalian heart, once extracellular matrix is established and cardiac cells exit the cell cycle, upregulation of extracellular matrix constituents reduces proliferation and causes formation of a collagenous stiff scar; cardiac regenerative capacity increases when extracellular matrix is less stiff [45] [46].

A second wave of immune activation has been described whereby upregulation of inflammation mediators in a distant organ, e.g. spleen, influences remodeling of the heart [33] [47]. Such a scenario could be used for the remote conditioning phenomenon that has been reported to confer considerable protection against ischemia-induced organ injury; remote conditioning could at- 
tenuate adverse myocardial remodeling by intercellular communications through extracellular vesicles, e.g. exosomes, which contain proteins, mRNAs, miRNAs (small noncoding RNAs) and DNA [48] [49]. MiRNAs are crucial for cardiac development and regeneration; [5] [50] they regulate target protein levels post-translationally by binding to complementary sequences in the untranslated region that leads to mRNA degradation or stop translation. Antifibrotic effects of specific miRNAs, e.g. miR-21, miR-29, etc., via exosome-mediated transmission [51] [52] could be affected by remote conditioning. Inhibition of miRNAs (cf. review by Soler-Botija [53]) may also reduce cardiomyocyte death; silencing various miRNA families in mice has been reported to protect the heart against effects of remodelling [54] [55]. Although less studied, recent findings support a role for noncoding RNAs (ncRNAs) in cardiomyocyte proliferation, but a more profound examination is necessary [56] [57].

Damage to the myocardial microvasculature, micro-embolization (neutrophil plugging, platelet aggregation, etc.) and external vascular compression caused by oedema all contribute to poor transmural perfusion following an ischemic event [58] [59]. Re-establishment of functional blood vessels is critical for delivery of oxygen and nutrients to ischemic myocardium; [60] either by re-opening of resident vessels or via angiogenesis within the infarct zone. Transplantation of bone mesenchymal stem cells (BMSCs) to infarcted myocardium promotes angiogenesis via release of angiogenic cytokines; [61] in rats, pretreatment with catalpol facilitates survival of BMSCs, inhibits apoptosis and increases vascular endothelial growth factor within ischemic myocardium [62] [63].

In zebrafish, delayed angiogenesis within the infarct zone reduces cardiomyocyte proliferation and results in nonresolution of scar [22] [64]. Additionally, in Hippo-deficient cardiomyocytes, upregulation of vasculogenesis [65] stimulates development of collateral vessel networks that are essential for tissue regeneration [66]. Furthermore, exogenous application of CXCL12 (chemotactic ligand induced by hypoxia) on the epicardium induces formation of collateral vessels by migration of arterial endothelial cells along pre-existing capillaries (arterial re-assembly) [66] [67]. An additional element of cardiac repair that is the formation of lymph vessels within the ischemic region; stimulation of lymphangiogenesis after infarction is necessary for removal of inflammatory cells and cellular by-products from the zone under repair [68]. Impeding formation of lymph vessels limits immune cell clearance and worsens clinical outcomes.

Cardiac interstitial cells such as myofibroblasts, infiltrating and tissue-resident macrophages, endothelial, stromal and other cell types [69] all help to regulate injury and regenerative responses but the factors responsible are not clear. A better understanding of complex interactions between signalling and developmental pathways of the various cell types that comprise the myocardium is essential for conception of novel clinical interventions. Heart regeneration may be limited with respect to location of injury within the ventricular wall; for instance, regeneration by activation of angiogenesis and formation of extracellular matrix 
have been documented in the epicardial layer [70] [71] [72]. While epicardial factors are important for cardiac regeneration after myocardial infarction, the reader is reminded that necrosis of the heart generally occurs first within the endocardial or deeper layers of the myocardial wall.

\section{Remote Cardiac Conditioning}

Remote cardiac conditioning was initially described as "preconditioning at a distance" by Przyklenk and coworkers [73]. Use of this intervention, before or after an ischemic event, markedly limits organ injury; repeated inflation/deflation of a blood pressure cuff on either an upper or a lower limb is generally used in patients [74] [75] [76]. A recent review of clinical studies that used remote conditioning reported, in about half of those studies, manifest cardiac protection; [77] the remainder documented either a positive trend, no benefit or even exacerbation of injury [8] [16]. Multiple comorbidities in patients may be responsible for the discordant results; however, cellular protection has been reported depending on the scale of stimulus used to trigger protective pathways [78].

The constancy of the level of protection against necrosis, ventricular dysrhythmias and contractile dysfunction provided by various conditioning strategies, e.g. anesthetic, pharmacologic, non-pharmacologic, direct and remote, etc. is remarkable. The commonality of underlying physiopathological mechanisms responsible for triggering cellular protection suggests the existence of cross-tolerance. Mechanisms involved in conditioning-mediated protection have been discussed elsewhere; as such, the reader is referred to a number of review articles that have examined intracellular signalling cascades and other mechanisms implicated in conditioning [1] [17] [79]. The benefits of conditioning on cardiac repair are known; protection afforded by non-pharmacologic interventions is potentially mediated by inhibition of extracellular matrix degradation and collagen synthesis [80] [81].

How protective signals, either humoral or neural, are transported from conditioned tissue to the target organ remain unclear. Diverse hypotheses have been examined and include communication: via blood or perfusate-borne humoral factors, by neuronal stimulation and transmission, and by systemic alteration of circulating immune cells [77] [82] [83]. Restoration of blood flow is key for initiating cellular protection; without it, transfer of mediators that trigger protective pathways to distant organs is questionable. Pharmacologic ganglionic blockade abrogates remote conditioning-mediated protection; this implies that protective signals are principally transferred via neural pathways [84] [85]. Integrity of cardiac nerve status influences immediate, or delayed conditioning-mediated cellular protection differently [86] [87] [88]. The requirement for intact and functional nerves is also questionable as nerve transection may abolish conditioning-induced protection; [89] but direct nerve stimulation can induce the protection phenotype [90] [91]. Exposure to brief periods of antecedent ischemia, i.e. ischemic conditioning, influences cardiomyocyte regeneration. 
Cellular protection with this intervention is either immediate, being triggered by release of endogenous mediators, e.g. adenosine, nitric oxide, bradykinin, etc. and activation of complex second messenger systems and anti-oxidant pathways, [92] [93] or delayed, being dependent on induction and release of cytoprotective proteins [94] [95].

Ischemic conditioning may stimulate angiogenesis within ischemic myocardium via release of various biochemical factors [96] and thereby improve perfusion at the microvessel level [97] but these findings remain controversial [98]. Improved availability of nutrients and oxygen within ischemic myocardium of conditioned hearts may be advantageous for tissue regenerative therapies.

\section{Heart Regeneration}

Myocardial injury stimulates cell cycle activation without mitosis; [99] multipotent cells with characteristics of cardiac stem cells can differentiate into myocytes, smooth muscle cells and endothelial cells [100]. Application of cardiomyocyte regeneration therapies to damaged myocardium is a promising therapeutic strategy for restoration of post-ischemic cardiac dysfunction. Progress of cardiomyocyte regenerative interventions is hindered by numerous challenges related to cell survival and engraftment post-injection.

During gestation, cardiomyocytes grow by hyperplasia (cellular division after duplication of entire cellular content) and by hypertrophy (increased cell size without increasing number) to increase overall mass [2] [101]. While the number of cardiomyocytes in the human heart is considered as fixed, [4] some proliferation and hypertrophy may occur with ageing due to activation of hormonal triggers [102]. The latter might also be due to loss of centrosome integrity and acytokinetic mitosis [103] [104]. Activators that interact with, and modulate, cyclin-CDK complexes, regulate progression through the cell cycle [2] [105] [106]. Species with regenerative capabilities comprise mononucleated and diploid cells; [107] more than 30 percent of adult cardiomyocytes are diploid [108]. Cardiomyocytes increase ploidy (i.e. number of chromosome sets) by acytokinetic mitosis, endomitosis and endoreduplication [109] [110]. Human cardiomyocytes reinitiate DNA synthesis (not associated with cardiomyocyte proliferation), without nuclear division, in response to various pathological conditions, e.g. hypertension, volume overload, valvular disease, etc. [111] Cardiomyocyte ploidy increases after myocardial infarction particularly within the border region (between injured and patent myocardium); [109] [112] the principal difference between non-regenerative and regenerative species is ploidy. Despite the increasing number of studies documenting improved cardiac performance in patients with ischemic heart disease benefitting from cardiomyocyte regenerative interventions, understanding the controlling mechanisms for cell cycle progression in humans is a challenge.

A host of genetic mechanisms are necessary for control of heart regeneration; a better understanding of these mechanisms is essential if we hope to improve 
success of interventions designed to stimulate cardiac repair. For instance, the Hippo pathway, i.e. evolutionarily conserved kinase cascade, is a key modulator of cardiac regeneration, cardiomyocyte replenishment, development, homeostasis, pathology and vascularity [113] [114]. Activation of the Hippo pathway leads to phosphorylation of transcriptional co-activators, e.g. YAP, TAZ, etc.; this prevents their nuclear localization and restrains cardiomyocyte proliferation [113] [115]. In mice, with myocardial infarction, deletion of core Hippo signalling components in cardiomyocytes leads to reversal of heart failure [50] [65].

Various other strategies are under investigation for regeneration of damaged myocardium post-infarction in patients; the most recent involves injection of stem cells to affected regions of the heart. To date, differentiation of stem cells to cardiomyocytes has proved to be underwhelming but some improvement of ventricular function has been reported [116]. Mechanisms advanced to explain these beneficial effects include paracrine actions, e.g. exosome-derived effects, which promote angiogenesis, mitigate apoptosis, modulate inflammation and subsequent scar formation or cardiac remodeling [117] [118].

Transplantation of cardiomyocytes, obtained from human heart or animal biopsies, into, or on, the injured heart is ongoing. A major limitation of most cell-based interventions is a lack of vascular support that is essential for the high oxygen and metabolic demands of contracting myocardium. Other factors that affect safety of cell delivery include; mode of delivery, cell type and dosage, status of the heart (contractile function, arrhythmic potential), time of treatment and adjunctive therapy used to enhance cellular homing and transdifferentiation [119]. Su and coworkers recently showed that a vascularized biomimetic microvessel patch promoted cardiomyocyte proliferation and neovascularization post-infarction [120]. Injectable collagen-based biomaterials could provide mechanical support, improve angiogenesis and tissue integration and limit negative remodelling; [121] [122] however, further testing is necessary to limit risks to patients [123]. McLaughlin and coworkers recently developed a recombinant human collagen matrix that prevents adverse cardiac remodelling but improves ventricular function even when applied during the late proliferative phase [124]. In immune-suppressed rats, transplantation of primary neonatal cardiomyocytes markedly enhanced ventricular function post-infarction [125] [126]. Similar findings are observed in other animal and clinical experiments; [127] [128] but this is not always the case in heart failure patients.

\section{Limitations}

While many studies advocate the promising aspects of cardiac regenerative techniques [129] there are limitations that underscore the optimism and benefits initially attributed to these interventions. For example, post transplantation almost 85 percent of donor stem cells are lost within the first $24 \mathrm{~h}$; [130] mitigating factors such as patient characteristics, e.g. sex, age, underlying medical conditions, etc., immune rejection of transplanted cells, obstruction of the micro- 
vasculature and tumor formation also merit consideration [131] [132]. Benefits of regenerative cell treatments may depend on myocardial location; success of stem cell or cardiomyocyte applications to the epicardial surface of the heart, which differ from intra-myocardial injections for a host of reasons amongst species. Moreover, a crucial missing element in this puzzle is the question of blood perfusion to the affected ischemic (i.e. microvessel level) area after, and during formation of scar, transplantation of regenerative cells or cellular scaffolds; rapid stimulation of neo-angiogenesis and neo-arteriogenesis to provide required nutrients and oxygen to newly formed myocardium has not been adequately documented. Successful implantation of cardiomyocytes, from human heart biopsies, across the myocardial wall surely depends on availability of blood perfusion at the macro- and micro-levels. Furthermore, information is lacking with respect to formation of a venous and lymphatic network that are critical for tissue viability.

Local effects of transplanted cells on diseased myocardium must also be evaluated. Resultant excessive inflammation or aberrant tissue formation, i.e. scar formation, tissue calcification, etc., could impair myocardial function [133]. Additionally, the in vivo regenerative capacity of other cell types essential for post-ischemic restoration of ventricular function remains uncertain [134] [135]. Nonetheless, ongoing efforts continue to search for ideal cell types and optimal treatment protocols including gene therapy; investigations are also underway to examine cell-free strategies aimed at multiple cell targets, e.g. cardiomyocytes, endothelial cells, etc. [136].

Despite the massive investment in regenerative interventions and therapy, studies show only modest improvement of ventricular contractile function; numerous clinical trials have reported unconvincingly that greater cardiac structure and function can be achieved in patients with ischemic heart disease. The regenerative capacity of mammalian myocardium remains questionable due to low-level re-entry of mature cardiomyocytes into the cell cycle; [137] [138] exogenously administered stem cells could be limited with regard to their capacity to stimulate myocardial repair or regeneration after pathological stress.

\section{Concluding Remarks}

Successful organ regeneration following acute myocardial infarction requires a perfect symphony between multiple micro-environmental factors, cardiac fibroblasts, extracellular matrix proteins, macrophages, redox status, etc., to stimulate or activate cellular signaling pathways or molecules that control the cardiomyocyte cell cycle. It is clear that numerous hurdles need to be overcome to ensure the re-organisation of functional myocardial structure after infarction. Finally, further evaluation in controlled large animal (i.e. non-rodent) or clinical studies is essential before cardiac regenerative interventions can be successfully applied to improve patient outcomes. A combinatorial treatment approach may turn out to be more effective than those aimed at single factors. For instance, in 
patients receiving remote conditioning interventions, a more favorable environment for proliferation of regenerative cell types within ischemic myocardium, e.g. due to less extensive ischemic injury, may be available. While this has not been examined in either animal or clinical studies, these questions must be addressed to ensure development of novel therapies to limit the effects of ischemic injury.

\section{Conflicts of Interest}

The author declares no conflicts of interest regarding the publication of this paper.

\section{References}

[1] Rosenberg, J.H., Werner, J.H., Moulton, M.J. and Agrawal, D.K. (2018) Current Modalities and Mechanisms Underlying Cardioprotection by Ischemic Conditioning. Journal of Cardiovascular Translational Research, 11, 292-307. https://doi.org/10.1007/s12265-018-9813-1

[2] Locatelli, P., Gimenez, C.S., Vega, M.U., Crottogini, A. and Belaich, M.N. (2019) Targeting the Cardiomyocyte Cell Cycle for Heart Regeneration. Current Drug Targets, 20, 241-254. https://doi.org/10.2174/1389450119666180801122551

[3] Murry, C.E., Reinecke, H. and Pabon, L.M. (2006) Regeneration Gaps: Observations on Stem Cells and Cardiac Repair. Journal of the American College of Cardiology, 47, 1777-1785. https://doi.org/10.1016/j.jacc.2006.02.002

[4] Bergmann, O., Zdunek, S., Felker, A., Salehpour, M., Alkass, K., Bernard, S., et al. (2015) Dynamics of Cell Generation and Turnover in the Human Heart. Cell, 161, 1566-1575. https://doi.org/10.1016/j.cell.2015.05.026

[5] Hashimoto, H., Olson, E.N. and Bassel-Duby, R. (2018) Therapeutic Approaches for Cardiac Regeneration and Repair. Nature Reviews Cardiology, 15, 585-600. https://doi.org/10.1038/s41569-018-0036-6

[6] Ye, L., D’Agostino, G., Loo, S.J., Wang, C.X., Su, L.P., Tan, S.H., et al. (2018) Early Regenerative Capacity in the Porcine Heart. Circulation, 138, 2798-2808. https://doi.org/10.1161/CIRCULATIONAHA.117.031542

[7] Jennings, R.B. (2013) Historical Perspective on the Pathology of Myocardial Ischemia/Reperfusion Injury. Circulation Research, 113, 428-438. https://doi.org/10.1161/CIRCRESAHA.113.300987

[8] Heusch, G. (2013) Cardioprotection: Chances and Challenges of Its Translation to the Clinic. The Lancet, 381, 166-175. https://doi.org/10.1016/S0140-6736(12)60916-7

[9] Bernink, F.J., Timmers, L., Beek, A.M., Diamant, M., Roos, S.T., Van Rossum, A.C., et al. (2014) Progression in Attenuating Myocardial Reperfusion Injury: An Overview. International Journal of Cardiology, 170, 261-269. https://doi.org/10.1016/j.ijcard.2013.11.007

[10] Leone, M. and Engel, F.B. (2019) Advances in Heart Regeneration Based on Cardiomyocyte Proliferation and Regenerative Potential of Binucleated Cardiomyocytes and Polyploidization. Clinical Science (London), 133, 1229-1253. https://doi.org/10.1042/CS20180560

[11] Sharma, A., Zhang, Y. and Wu, S.M. (2015) Harnessing the Induction of Cardiomyocyte Proliferation for Cardiac Regenerative Medicine. Current Treatment Op- 
tions in Cardiovascular Medicine, 17, 404.

https://doi.org/10.1007/s11936-015-0404-Z

[12] Li, Y., He, L., Huang, X., Bhaloo, S.I., Zhao, H., Zhang, S., et al. (2018) Genetic Lineage Tracing of Nonmyocyte Population by Dual Recombinases. Circulation, 138, 793-805. https://doi.org/10.1161/CIRCULATIONAHA.118.034250

[13] Laflamme, M.A. and Murry, C.E. (2011) Heart Regeneration. Nature, 473, 326-335. https://doi.org/10.1038/nature10147

[14] Murry, C.E., Jennings, R.B. and Reimer, K.A. (1986) Preconditioning with Ischemia: A Delay of Lethal Cell Injury in Ischemic Myocardium. Circulation, 74, 1124-1136. https://doi.org/10.1161/01.CIR.74.5.1124

[15] Kingma, J.G. (2014) Conditioning Strategies Limit Cellular Injury? World Journal of Cardiovascular Diseases, 4, 539-547. https://doi.org/10.4236/wjcd.2014.411065

[16] Ovize, M., Thibault, H. and Przyklenk, K. (2013) Myocardial Conditioning: Opportunities for Clinical Translation. Circulation Research, 113, 439-450. https://doi.org/10.1161/CIRCRESAHA.113.300764

[17] Hausenloy, D.J., Barrabes, J.A., Botker, H.E., Davidson, S.M., Di Lisa, F., Downey, J., et al. (2016) Ischaemic Conditioning and Targeting Reperfusion Injury: A 30 Year Voyage of Discovery. Basic Research in Cardiology, 111, 70. https://doi.org/10.1007/s00395-016-0588-8

[18] Ganote, C.E. (1983) Contraction Band Necrosis and Irreversible Myocardial Injury. Journal of Molecular and Cellular Cardiology, 15, 67-73. https://doi.org/10.1016/0022-2828(83)90283-3

[19] Konstantinidis, K., Whelan, R.S. and Kitsis, R.N. (2012) Mechanisms of Cell Death in Heart Disease. Arteriosclerosis, Thrombosis, and Vascular Biology, 32, 1552-1562. https://doi.org/10.1161/ATVBAHA.111.224915

[20] Ibanez, B., Heusch, G., Ovize, M. and Van de Werf, F. (2015) Evolving Therapies for Myocardial Ischemia/Reperfusion Injury. Journal of the American College of Cardiology, 65, 1454-1471. https://doi.org/10.1016/j.jacc.2015.02.032

[21] Weil, B.R. and Neelamegham, S. (2019) Selectins and Immune Cells in Acute Myocardial Infarction and Post-Infarction Ventricular Remodeling: Pathophysiology and Novel Treatments. Frontiers in Immunology, 10, 300. https://doi.org/10.3389/fimmu.2019.00300

[22] Lai, S.L., Marin-Juez, R. and Stainier, D.Y.R. (2019) Immune Responses in Cardiac Repair and Regeneration: A Comparative Point of View. Cellular and Molecular Life Sciences, 76, 1365-1380. https://doi.org/10.1007/s00018-018-2995-5

[23] Rutkowski, M.J., Sughrue, M.E., Kane, A.J., Ahn, B.J., Fang, S. and Parsa, A.T. (2010) The Complement Cascade as a Mediator of Tissue Growth and Regeneration. Inflammation Research, 59, 897-905. https://doi.org/10.1007/s00011-010-0220-6

[24] Dick, S.A., Macklin, J.A., Nejat, S., Momen, A., Clemente-Casares, X., Althagafi, M.G., et al. (2019) Self-Renewing Resident Cardiac Macrophages Limit Adverse Remodeling Following Myocardial Infarction. Nature Immunology, 20, 29-39. https://doi.org/10.1038/s41590-018-0272-2

[25] Ma, Y., Yabluchanskiy, A. and Lindsey, M.L. (2013) Neutrophil Roles in Left Ventricular Remodeling Following Myocardial Infarction. Fibrogenesis \& Tissue Repair, 6, 11. https://doi.org/10.1186/1755-1536-6-11

[26] Heusch, G. (2016) The Coronary Circulation as a Target of Cardioprotection. Circulation Research, 118, 1643-1658. 


\section{https://doi.org/10.1161/CIRCRESAHA.116.308640}

[27] Timmers, L., Pasterkamp, G., de Hoog, V.C., Arslan, F., Appelman, Y. and de Kleijn, D.P. (2012) The Innate Immune Response in Reperfused Myocardium. Cardiovascular Research, 94, 276-283. https://doi.org/10.1093/cvr/cvs018

[28] Panizzi, P., Swirski, F.K., Figueiredo, J.L., Waterman, P., Sosnovik, D.E., Aikawa, E., et al. (2010) Impaired Infarct Healing in Atherosclerotic Mice with Ly-6C(hi) Monocytosis. Journal of the American College of Cardiology, 55, 1629-1638. https://doi.org/10.1016/j.jacc.2009.08.089

[29] Cochain, C., Auvynet, C., Poupel, L., Vilar, J., Dumeau, E., Richart, A., et al. (2012) The Chemokine Decoy Receptor D6 Prevents Excessive Inflammation and Adverse Ventricular Remodeling after Myocardial Infarction. Arteriosclerosis, Thrombosis, and Vascular Biology, 32, 2206-2213. https://doi.org/10.1161/ATVBAHA.112.254409

[30] Natarajan, N., Abbas, Y., Bryant, D.M., Gonzalez-Rosa, J.M., Sharpe, M., Uygur, A., et al. (2018) Complement Receptor C5aR1 Plays an Evolutionarily Conserved Role in Successful Cardiac Regeneration. Circulation, 137, 2152-2165. https://doi.org/10.1161/CIRCULATIONAHA.117.030801

[31] Nahrendorf, M., Pittet, M.J. and Swirski, F.K. (2010) Monocytes: Protagonists of Infarct Inflammation and Repair after Myocardial Infarction. Circulation, 121, 2437-2445. https://doi.org/10.1161/CIRCULATIONAHA.109.916346

[32] Sanchez-Alonso, S., Alcaraz-Serna, A., Sanchez-Madrid, F. and Alfranca, A. (2018) Extracellular Vesicle-Mediated Immune Regulation of Tissue Remodeling and Angiogenesis after Myocardial Infarction. Frontiers in Immunology, 9, 2799. https://doi.org/10.3389/fimmu.2018.02799

[33] Prabhu, S.D. and Frangogiannis, N.G. (2016) The Biological Basis for Cardiac Repair after Myocardial Infarction: From Inflammation to Fibrosis. Circulation Research, 119, 91-112. https://doi.org/10.1161/CIRCRESAHA.116.303577

[34] Hofmann, U., Beyersdorf, N., Weirather, J., Podolskaya, A., Bauersachs, J., Ertl, G., et al. (2012) Activation of CD4+ T Lymphocytes Improves Wound Healing and Survival after Experimental Myocardial Infarction in Mice. Circulation, 125, 1652-1663. https://doi.org/10.1161/CIRCULATIONAHA.111.044164

[35] Shinde, A.V., Humeres, C. and Frangogiannis, N.G. (2017) The Role of Alpha-Smooth Muscle Actin in Fibroblast-Mediated Matrix Contraction and Remodeling. BBA Molecular Basis of Disease, 1863, 298-309.

https://doi.org/10.1016/j.bbadis.2016.11.006

[36] Yano, T., Miura, T., Ikeda, Y., Matsuda, E., Saito, K., Miki, T., et al. (2005) Intracardiac Fibroblasts, But Not Bone Marrow Derived Cells, Are the Origin of Myofibroblasts in Myocardial Infarct Repair. Cardiovascular Pathology, 14, 241-246. https://doi.org/10.1016/j.carpath.2005.05.004

[37] Mollmann, H., Nef, H.M., Kostin, S., von Kalle, C., Pilz, I., Weber, M., et al. (2006) Bone Marrow-Derived Cells Contribute to Infarct Remodelling. Cardiovascular Research, 71, 661-671. https://doi.org/10.1016/j.cardiores.2006.06.013

[38] Dobaczewski, M., de Haan, J.J. and Frangogiannis, N.G. (2012) The Extracellular Matrix Modulates Fibroblast Phenotype and Function in the Infarcted Myocardium. Journal of Cardiovascular Translational Research, 5, 837-847. https://doi.org/10.1007/s12265-012-9406-3

[39] Frangogiannis, N.G. (2017) The Extracellular Matrix in Myocardial Injury, Repair, and Remodeling. Journal of Clinical Investigation, 127, 1600-1612.

https://doi.org/10.1172/JCI87491 
[40] He, Q., Wang, F., Honda, T., James, J., Li, J. and Redington, A. (2018) Loss of miR-144 Signaling Interrupts Extracellular Matrix Remodeling after Myocardial Infarction Leading to Worsened Cardiac Function. Scientific Reports, 8, Article No. 16886. https://doi.org/10.1038/s41598-018-35314-6

[41] Voorhees, A.P., DeLeon-Pennell, K.Y., Ma, Y., Halade, G.V., Yabluchanskiy, A., Iyer, R.P., et al. (2015) Building a Better Infarct: Modulation of Collagen Cross-Linking to Increase Infarct Stiffness and Reduce Left Ventricular Dilation Post-Myocardial Infarction. Journal of Molecular and Cellular Cardiology, 85, 229-239. https://doi.org/10.1016/j.yjmcc.2015.06.006

[42] Lopez, B., Ravassa, S., Gonzalez, A., Zubillaga, E., Bonavila, C., Berges, M., et al. (2016) Myocardial Collagen Cross-Linking Is Associated with Heart Failure Hospitalization in Patients with Hypertensive Heart Failure. Journal of the American College of Cardiology, 67, 251-260. https://doi.org/10.1016/j.jacc.2015.10.063

[43] Hearse, D.J. and Yellon, D.M. (1981) The "Border Zone" in Evolving Myocardial Infarction: Controversy or Confusion? American Journal of Cardiology, 47, 1321-1334. https://doi.org/10.1016/0002-9149(81)90266-6

[44] Hearse, D.J. and Yellon, D.M. (1981) The "Border Zone" and Myocardial Protection: A Time for Reassessment? Acta Medica Scandinavica. Supplementum, 651, 37-46. https://doi.org/10.1111/j.0954-6820.1981.tb03630.x

[45] Hortells, L., Johansen, A.K.Z. and Yutzey, K.E. (2019) Cardiac Fibroblasts and the Extracellular Matrix in Regenerative and Nonregenerative Hearts. Journal of Cardiovascular Development and Disease, 6, pii: E29. https://doi.org/10.3390/jcdd6030029

[46] Notari, M., Ventura-Rubio, A., Bedford-Guaus, S.J., Jorba, I., Mulero, L., Navajas, D., et al. (2018) The Local Microenvironment Limits the Regenerative Potential of the Mouse Neonatal Heart. Science Advances, 4, eaao5553.

https://doi.org/10.1126/sciadv.aao5553

[47] Ismahil, M.A., Hamid, T., Bansal, S.S., Patel, B., Kingery, J.R. and Prabhu, S.D. (2014) Remodeling of the Mononuclear Phagocyte Network Underlies Chronic Inflammation and Disease Progression in Heart Failure: Critical Importance of the Cardiosplenic Axis. Circulation Research, 114, 266-282. https://doi.org/10.1161/CIRCRESAHA.113.301720

[48] Yamaguchi, T., Izumi, Y., Nakamura, Y., Yamazaki, T., Shiota, M., Sano, S., et al. (2015) Repeated Remote Ischemic Conditioning Attenuates Left Ventricular Remodeling via Exosome-Mediated Intercellular Communication on Chronic Heart Failure after Myocardial Infarction. International Journal of Cardiology, 178, 239-246. https://doi.org/10.1016/j.ijcard.2014.10.144

[49] Creemers, E.E., Tijsen, A.J. and Pinto, Y.M. (2012) Circulating microRNAs: Novel Biomarkers and Extracellular Communicators in Cardiovascular Disease? Circulation Research, 110, 483-495. https://doi.org/10.1161/CIRCRESAHA.111.247452

[50] Deshmukh, V., Wang, J. and Martin, J.F. (2019) Leading Progress in Heart Regeneration and Repair. Current Opinion in Cell Biology, 61, 79-85. https://doi.org/10.1016/j.ceb.2019.07.005

[51] van Rooij, E., Sutherland, L.B., Thatcher, J.E., DiMaio, J.M., Naseem, R.H., Marshall, W.S., et al. (2008) Dysregulation of microRNAs after Myocardial Infarction Reveals a Role of miR-29 in Cardiac Fibrosis. Proceedings of the National Academy of Sciences of the United States of America, 105, 13027-13032. https://doi.org/10.1073/pnas.0805038105

[52] Zhu, H. and Fan, G.C. (2012) Role of microRNAs in the Reperfused Myocardium 
towards Post-Infarct Remodelling. Cardiovascular Research, 94, 284-292. https://doi.org/10.1093/cvr/cvr291

[53] Soler-Botija, C., Forcales, S.V. and Bayes Genis, A. (2020) Spotlight on Epigenetic Reprogramming in Cardiac Regeneration. Seminars in Cell and Developmental Biology, 97, 26-37. https://doi.org/10.1016/j.semcdb.2019.04.009

[54] Meloni, M., Marchetti, M., Garner, K., Littlejohns, B., Sala-Newby, G., Xenophontos, N., et al. (2013) Local Inhibition of microRNA-24 Improves Reparative Angiogenesis and Left Ventricle Remodeling and Function in Mice with Myocardial Infarction. Molecular Therapy, 21, 1390-1402. https://doi.org/10.1038/mt.2013.89

[55] Tony, H., Meng, K., Wu, B., Yu, A., Zeng, Q., Yu, K., et al. (2015) MicroRNA-208a Dysregulates Apoptosis Genes Expression and Promotes Cardiomyocyte Apoptosis during Ischemia and Its Silencing Improves Cardiac Function after Myocardial Infarction. Mediators of Inflammation, 2015, Article ID: 479123.

https://doi.org/10.1155/2015/479123

[56] Ounzain, S., Micheletti, R., Arnan, C., Plaisance, I., Cecchi, D., Schroen, B., et al. (2015) CARMEN, a Human Super Enhancer-Associated Long Noncoding RNA Controlling Cardiac Specification, Differentiation and Homeostasis. Journal of Molecular and Cellular Cardiology, 89, 98-112.

https://doi.org/10.1016/j.yjmcc.2015.09.016

[57] Verjans, R., van Bilsen, M. and Schroen, B. (2020) Reviewing the Limitations of Adult Mammalian Cardiac Regeneration: Noncoding RNAs as Regulators of Cardiomyogenesis. Biomolecules, 10, 262. https://doi.org/10.3390/biom10020262

[58] Heusch, G., Kleinbongard, P., Bose, D., Levkau, B., Haude, M., Schulz, R., et al. (2009) Coronary Microembolization: From Bedside to Bench and Back to Bedside. Circulation, 120, 1822-1836. https://doi.org/10.1161/CIRCULATIONAHA.109.888784

[59] Kingma, J.G. (2013) The Myocardial Microcirculation: A Key Target for Salvaging Ischemic Myocardium? World Journal of Cardiovascular Diseases, 3, 8-16. https://doi.org/10.4236/wjcd.2013.35A002

[60] Meoli, D.F., Sadeghi, M.M., Krassilnikova, S., Bourke, B.N., Giordano, F.J., Dione, D.P., et al. (2004) Noninvasive Imaging of Myocardial Angiogenesis Following Experimental Myocardial Infarction. Journal of Clinical Investigation, 113, 1684-1691. https://doi.org/10.1172/JCI200420352

[61] Rahbarghazi, R., Nassiri, S.M., Ahmadi, S.H., Mohammadi, E., Rabbani, S., Araghi, A., et al. (2014) Dynamic Induction of Pro-Angiogenic Milieu after Transplantation of Marrow-Derived Mesenchymal Stem Cells in Experimental Myocardial Infarction. International Journal of Cardiology, 173, 453-466. https://doi.org/10.1016/j.ijcard.2014.03.008

[62] Dong, W., et al. (2016) Catalpol Stimulates VEGF Production via the JAK2/STAT3 Pathway to Improve Angiogenesis in Rats' Stroke Model. Journal of Ethnopharmacology, 191, 169-179. https://doi.org/10.1016/j.jep.2016.06.030

[63] Ju, X., Xue, D., Wang, T., Ge, B., Zhang, Y. and Li, Z. (2018) Catalpol Promotes the Survival and VEGF Secretion of Bone Marrow-Derived Stem Cells and Their Role in Myocardial Repair after Myocardial Infarction in Rats. Cardiovascular Toxicology, 18, 471-481. https://doi.org/10.1007/s12012-018-9460-4

[64] Marin-Juez, R., Marass, M., Gauvrit, S., Rossi, A., Lai, S.L., Materna, S., et al. (2016) Fast Revascularization of the Injured Area Is Essential to Support Zebrafish Heart Regeneration. Proceedings of the National Academy of Sciences of the United States of America, 113, 11237-11242. https://doi.org/10.1073/pnas.1605431113 
[65] Leach, J.P., Heallen, T., Zhang, M., Rahmani, M., Morikawa, Y., Hill, M.C., et al. (2017) Hippo Pathway Deficiency Reverses Systolic Heart Failure after Infarction. Nature, 550, 260-264. https://doi.org/10.1038/nature24045

[66] Das, S., Goldstone, A.B., Wang, H., Farry, J., D’Amato, G., Paulsen, M.J., et al. (2019) A Unique Collateral Artery Development Program Promotes Neonatal Heart Regeneration. Cell, 176, 1128-1142.e18. https://doi.org/10.1016/j.cell.2018.12.023

[67] Dube, K.N., Thomas, T.M., Munshaw, S., Rohling, M., Riley, P.R. and Smart, N. (2017) Recapitulation of Developmental Mechanisms to Revascularize the Ischemic Heart. JCI Insight, 2, pii: 96800. https://doi.org/10.1172/jci.insight.96800

[68] Vieira, J.M., Norman, S., Villa Del Campo, C., Cahill, T.J., Barnette, D.N., Gunadasa-Rohling, M., et al. (2018) The Cardiac Lymphatic System Stimulates Resolution of Inflammation Following Myocardial Infarction. Journal of Clinical Investigation, 128, 3402-3412. https://doi.org/10.1172/JCI97192

[69] Farbehi, N., Patrick, R., Dorison, A., Xaymardan, M., Janbandhu, V., Wystub-Lis, K., et al. (2019) Single-Cell Expression Profiling Reveals Dynamic Flux of Cardiac Stromal, Vascular and Immune Cells in Health and Injury. Elife, 8, pii: e43882. https://doi.org/10.7554/eLife.43882

[70] Saifi, O., Ghandour, B., Jaalouk, D., Refaat, M. and Mahfouz, R. (2019) Myocardial Regeneration: Role of Epicardium and Implicated Genes. Molecular Biology Reports, 46, 6661-6674. https://doi.org/10.1007/s11033-019-05075-0

[71] Uygur, A. and Lee, R.T. (2016) Mechanisms of Cardiac Regeneration. Developmental Cell, 36, 362-374. https://doi.org/10.1016/j.devcel.2016.01.018

[72] Smart, N., Dube, K.N. and Riley, P.R. (2013) Epicardial Progenitor Cells in Cardiac Regeneration and Neovascularisation. Vascular Pharmacology, 58, 164-173. https://doi.org/10.1016/j.vph.2012.08.001

[73] Przyklenk, K., Bauer, B., Ovize, M., Kloner, R.A. and Whittaker, P. (1993) Regional Ischemic Preconditioning Protects Remote Virgin Myocardium from Subsequent Coronary Occlusion. Circulation, 87, 893-899. https://doi.org/10.1161/01.CIR.87.3.893

[74] Konstantinov, I.E., Li, J., Cheung, M.M., Shimizu, M., Stokoe, J., Kharbanda, R.K., et al. (2005) Remote Ischemic Preconditioning of the Recipient Reduces Myocardial Ischemia-Reperfusion Injury of the Denervated Donor Heart via a Katp Channel-Dependent Mechanism. Transplantation, 79, 1691-1695. https://doi.org/10.1097/01.TP.0000159137.76400.5D

[75] Shimizu, M., Konstantinov, I.E., Kharbanda, R.K., Cheung, M.H. and Redington, A.N. (2007) Effects of Intermittent Lower Limb Ischaemia on Coronary Blood Flow and Coronary Resistance in Pigs. Acta Physiologica, 190, 103-109.

https://doi.org/10.1111/j.1748-1716.2007.01667.x

[76] Kharbanda, R.K., Mortensen, U.M., White, P.A., Kristiansen, S.B., Schmidt, M.R., Hoschtitzky, J.A., et al. (2002) Transient Limb Ischemia Induces Remote Ischemic Preconditioning in Vivo. Circulation, 106, 2881-2883. https://doi.org/10.1161/01.CIR.0000043806.51912.9B

[77] Przyklenk, K. (2013) Reduction of Myocardial Infarct Size with Ischemic "Conditioning": Physiologic and Technical Considerations. Anesthesia \& Analgesia, 117, 891-901. https://doi.org/10.1213/ANE.0b013e318294fc63

[78] Tsang, A., Hausenloy, D.J., Mocanu, M.M., Carr, R.D. and Yellon, D.M. (2005) Preconditioning the Diabetic Heart: The Importance of Akt Phosphorylation. Diabetes, 54, 2360-2364. https://doi.org/10.2337/diabetes.54.8.2360

[79] Przyklenk, K. (2015) Ischaemic Conditioning: Pitfalls on the Path to Clinical Trans- 
lation. British Journal of Pharmacology, 172, 1961-1973. https://doi.org/10.1111/bph.13064

[80] Bell, R.M. and Yellon, D.M. (2012) Conditioning the Whole Heart-Not Just the Cardiomyocyte. Journal of Molecular and Cellular Cardiology, 53, 24-32. https://doi.org/10.1016/j.yjmcc.2012.04.001

[81] Granfeldt, A., Jiang, R., Wang, N.P., Mykytenko, J., Eldaif, S., Deneve, J., et al. (2012) Neutrophil Inhibition Contributes to Cardioprotection by Postconditioning. Acta Anaesthesiologica Scandinavica, 56, 48-56. https://doi.org/10.1111/j.1399-6576.2011.02577.x

[82] Weber, C. (2010) Far from the Heart: Receptor Cross-Talk in Remote Conditioning. Nature Medicine, 16, 760-762. https://doi.org/10.1038/nm0710-760

[83] Dickson, E.W., Tubbs, R.J., Porcaro, W.A., Lee, W.J., Blehar, D.J., Carraway, R.E., et al. (2002) Myocardial Preconditioning Factors Evoke Mesenteric Ischemic Tolerance via Opioid Receptors and K(ATP) Channels. The American Journal of Physiology-Heart and Circulatory Physiology, 283, H22-H28.

https://doi.org/10.1152/ajpheart.01055.2001

[84] Weinbrenner, C., Nelles, M., Herzog, N., Sarvary, L. and Strasser, R.H. (2002) Remote Preconditioning by Infrarenal Occlusion of the Aorta Protects the Heart from Infarction: A Newly Identified Non-Neuronal But PKC-Dependent Pathway. Cardiovascular Research, 55, 590-601. https://doi.org/10.1016/S0008-6363(02)00446-7

[85] Loukogeorgakis, S.P., Panagiotidou, A.T., Broadhead, M.W., Donald, A., Deanfield, J.E. and MacAllister, R.J. (2005) Remote Ischemic Preconditioning Provides Early and Late Protection against Endothelial Ischemia-Reperfusion Injury in Humans: Role of the Autonomic Nervous System. Journal of the American College of Cardiology, 46, 450-456. https://doi.org/10.1016/j.jacc.2005.04.044

[86] Kudej, R.K., Shen, Y.T., Peppas, A.P., Huang, C.H., Chen, W., Yan, L., et al. (2006) Obligatory Role of Cardiac Nerves and Alpha1-Adrenergic Receptors for the Second Window of Ischemic Preconditioning in Conscious Pigs. Circulation Research, 99, 1270-1276. https://doi.org/10.1161/01.RES.0000251282.79411.44

[87] Ardell, J.L., Yang, X.-M., Barron, B.A., Downey, J.M. and Cohen, M.V. (1996) Endogenous Myocardial Norepinephrine Is Not Essential for Ischemic Preconditioning in Rabbit Heart. The American Journal of Physiology-Heart and Circulatory Physiology, 270, H1078-H1084. https://doi.org/10.1152/ajpheart.1996.270.3.H1078

[88] Kingma, J.G., Simard, D., Voisine, P. and Rouleau, J.R. (2011) Role of the Autonomic Nervous System in Cardioprotection by Remote Preconditioning in Isoflurane-Anaesthetized Dogs. Cardiovascular Research, 89, 384-391.

https://doi.org/10.1093/cvr/cvq306

[89] Steensrud, T., Li, J., Dai, X., Manlhiot, C., Kharbanda, R.K., Tropak, M., et al. (2010) Pretreatment with the Nitric Oxide Donor SNAP or Nerve Transection Blocks Humoral Preconditioning by Remote Limb Ischemia or Intra-Arterial Adenosine. The American Journal of Physiology-Heart and Circulatory Physiology, 299, H1598-H1603. https://doi.org/10.1152/ajpheart.00396.2010

[90] Merlocco, A.C., Redington, K.L., Disenhouse, T., Strantzas, S.C., Gladstone, R., Wei, C., et al. (2014) Transcutaneous Electrical Nerve Stimulation as a Novel Method of Remote Preconditioning: In Vitro Validation in an Animal Model and First Human Observations. Basic Research in Cardiology, 109, 406. https://doi.org/10.1007/s00395-014-0406-0

[91] Redington, K.L., Disenhouse, T., Li, J., Wei, C., Dai, X., Gladstone, R., et al. (2013) Electroacupuncture Reduces Myocardial Infarct Size and Improves Post-Ischemic 
Recovery by Invoking Release of Humoral, Dialyzable, Cardioprotective Factors. The Journal of Physiological Sciences, 63, 219-223. https://doi.org/10.1007/s12576-013-0259-6

[92] Dawn, B. and Bolli, R. (2002) Role of Nitric Oxide in Myocardial Preconditioning. Annals of the New York Academy of Sciences, 962, 18-41. https://doi.org/10.1111/j.1749-6632.2002.tb04053.x

[93] Murphy, E. and Steenbergen, C. (2008) Mechanisms Underlying Acute Protection from Cardiac Ischemia-Reperfusion Injury. Physiological Reviews, 88, 581-609. https://doi.org/10.1152/physrev.00024.2007

[94] Bolli, R. (2000) The Late Phase of Preconditioning. Circulation Research, 87, 972-983. https://doi.org/10.1161/01.RES.87.11.972

[95] Currie, R.W., Tanguay, R.M. and Kingma, J.G. (1993) Heat-Shock Response and Limitation of Tissue Necrosis during Occlusion/Reperfusion in Rabbit Hearts. Circulation, 87, 963-971. https://doi.org/10.1161/01.RES.87.11.972

[96] Hausenloy, D.J. and Yellon, D.M. (2008) Remote Ischaemic Preconditioning: Underlying Mechanisms and Clinical Application. Cardiovascular Research, 79, 377-386. https://doi.org/10.1093/cvr/cvn114

[97] Wang, W.Z., Stepheson, L.L., Fang, X.H., Khiabani, K.T. and Zamboni, W.A. (2004) Ischemic Preconditioning-Induced Microvascular Protection at a Distance. Journal of Reconstructive Microsurgery, 20, 175-181. https://doi.org/10.1055/s-2004-820775

[98] Karakoyun, R., Koksoy, C., Yilmaz, T.U., Altun, H., Banli, O., Albayrak, A., et al. (2014) The Angiogenic Effects of Ischemic Conditioning in Experimental Critical Limb Ischemia. European Journal of Vascular and Endovascular Surgery, 47, 172-179. https://doi.org/10.1016/j.ejvs.2013.11.001

[99] Rumyantsev, P.P. (1977) Interrelations of the Proliferation and Differentiation Processes during Cardiact Myogenesis and Regeneration. International Review of Cytology, 51, 186-273. https://doi.org/10.1016/S0074-7696(08)60228-4

[100] Beltrami, A.P., Barlucchi, L., Torella, D., Baker, M., Limana, F., Chimenti, S., et al. (2003) Adult Cardiac Stem Cells Are Multipotent and Support Myocardial Regeneration. Cell, 114, 763-776. https://doi.org/10.1016/S0092-8674(03)00687-1

[101] Li, F., Wang, X., Capasso, J.M. and Gerdes, A.M. (1996) Rapid Transition of Cardiac Myocytes from Hyperplasia to Hypertrophy during Postnatal Development. Journal of Molecular and Cellular Cardiology, 28, 1737-1746. https://doi.org/10.1006/jmcc.1996.0163

[102] Naqvi, N., Li, M., Calvert, J.W., Tejada, T., Lambert, J.P., Wu, J., et al. (2014) A Proliferative Burst during Preadolescence Establishes the Final Cardiomyocyte Number. Cell, 157, 795-807. https://doi.org/10.1016/j.cell.2014.03.035

[103] Zebrowski, D.C., Vergarajauregui, S., Wu, C.C., Piatkowski, T., Becker, R., Leone, M., et al. (2015) Developmental Alterations in Centrosome Integrity Contribute to the Post-Mitotic State of Mammalian Cardiomyocytes. Elife, 4, e05563. https://doi.org/10.7554/eLife.05563

[104] Engel, F.B., Schebesta, M. and Keating, M.T. (2006) Anillin Localization Defect in Cardiomyocyte Binucleation. Journal of Molecular and Cellular Cardiology, 41, 601-612. https://doi.org/10.1016/j.yimcc.2006.06.012

[105] Brooks, G., Poolman, R.A. and Li, J.M. (1998) Arresting Developments in the Cardiac Myocyte Cell Cycle: Role of Cyclin-Dependent Kinase Inhibitors. Cardiovascular Research, 39, 301-311. https://doi.org/10.1016/S0008-6363(98)00125-4

[106] Woo, R.A. and Poon, R.Y. (2003) Cyclin-Dependent Kinases and S Phase Control in 
Mammalian Cells. Cell Cycle, 2, 316-324. https://doi.org/10.4161/cc.2.4.468

[107] Hirose, K., Payumo, A.Y., Cutie, S., Hoang, A., Zhang, H., Guyot, R., et al. (2019) Evidence for Hormonal Control of Heart Regenerative Capacity during Endothermy Acquisition. Science, 364, 184-188. https://doi.org/10.1126/science.aar2038

[108] Mollova, M., Bersell, K., Walsh, S., Savla, J., Das, L.T., Park, S.Y., et al. (2013) Cardiomyocyte Proliferation Contributes to Heart Growth in Young Humans. Proceedings of the National Academy of Sciences of the United States of America, 110, 1446-1151. https://doi.org/10.1073/pnas.1214608110

[109] Meckert, P.C., Rivello, H.G., Vigliano, C., Gonzalez, P., Favaloro, R. and Laguens, R. (2005) Endomitosis and Polyploidization of Myocardial Cells in the Periphery of Human Acute Myocardial Infarction. Cardiovascular Research, 67, 116-123. https://doi.org/10.1016/j.cardiores.2005.02.017

[110] Hesse, M., Raulf, A., Pilz, G.A., Haberlandt, C., Klein, A.M., Jabs, R., et al. (2012) Direct Visualization of Cell Division Using High-Resolution Imaging of M-Phase of the Cell Cycle. Nature Communications, 3, 1076.

https://doi.org/10.1038/ncomms2089

[111] Adler, C.P. and Friedburg, H. (1986) Myocardial DNA Content, Ploidy Level and Cell Number in Geriatric Hearts: Post-Mortem Examinations of Human Myocardium in Old Age. Journal of Molecular and Cellular Cardiology, 18, 39-53. https://doi.org/10.1016/S0022-2828(86)80981-6

[112] Senyo, S.E., Steinhauser, M.L., Pizzimenti, C.L., Yang, V.K., Cai, L., Wang, M., et al. (2013) Mammalian Heart Renewal by Pre-Existing Cardiomyocytes. Nature, 493, 433-436. https://doi.org/10.1038/nature11682

[113] Wang, J., Liu, S., Heallen, T. and Martin, J.F. (2018) The Hippo Pathway in the Heart: Pivotal Roles in Development, Disease, and Regeneration. Nature Reviews Cardiology, 15, 672-684. https://doi.org/10.1038/s41569-018-0063-3

[114] Castellan, R.F.P. and Meloni, M. (2018) Mechanisms and Therapeutic Targets of Cardiac Regeneration: Closing the Age Gap. Frontiers in Cardiovascular Medicine, 5, 7. https://doi.org/10.3389/fcvm.2018.00007

[115] Heallen, T., Zhang, M., Wang, J., Bonilla-Claudio, M., Klysik, E., Johnson, R.L., et al. (2011) Hippo Pathway Inhibits Wnt Signaling to Restrain Cardiomyocyte Proliferation and Heart Size. Science, 332, 458-461. https://doi.org/10.1126/science.1199010

[116] Fernandez-Aviles, F., Sanz-Ruiz, R., Climent, A.M., Badimon, L., Bolli, R., Charron, D., et al. (2017) Global Position Paper on Cardiovascular Regenerative Medicine. European Heart Journal, 38, 2532-2546. https://doi.org/10.1093/eurheartj/ehx248

[117] Mirotsou, M., Jayawardena, T.M., Schmeckpeper, J., Gnecchi, M. and Dzau, V.J. (2011) Paracrine Mechanisms of Stem Cell Reparative and Regenerative Actions in the Heart. Journal of Molecular and Cellular Cardiology, 50, 280-289. https://doi.org/10.1016/j.yjmcc.2010.08.005

[118] Liu, Y.W., Chen, B., Yang, X., Fugate, J.A., Kalucki, F.A., Futakuchi-Tsuchida, A., et al. (2018) Human Embryonic Stem Cell-Derived Cardiomyocytes Restore Function in Infarcted Hearts of Non-Human Primates. Nature Biotechnology, 36, 597-605. https://doi.org/10.1038/nbt.4162

[119] Ben-Dor, I., Fuchs, S. and Kornowski, R. (2006) Potential Hazards and Technical Considerations Associated with Myocardial Cell Transplantation Protocols for Ischemic Myocardial Syndrome. Journal of the American College of Cardiology, 48, 1519-1526. https://doi.org/10.1016/j.jacc.2006.06.058

[120] Su, T., Huang, K., Daniele, M.A., Hensley, M.T., Young, A.T., Tang, J., et al. (2018) 
Cardiac Stem Cell Patch Integrated with Microengineered Blood Vessels Promotes Cardiomyocyte Proliferation and Neovascularization after Acute Myocardial Infarction. ACS Applied Materials \& Interfaces, 10, 33088-33096.

https://doi.org/10.1021/acsami.8b13571

[121] Blackburn, N.J., Sofrenovic, T., Kuraitis, D., Ahmadi, A., McNeill, B., Deng, C., et al. (2015) Timing Underpins the Benefits Associated with Injectable Collagen Biomaterial Therapy for the Treatment of Myocardial Infarction. Biomaterials, 39, 182-192. https://doi.org/10.1016/j.biomaterials.2014.11.004

[122] Ahmadi, A., McNeill, B., Vulesevic, B., Kordos, M., Mesana, L., Thorn, S., et al. (2014) The Role of Integrin alpha2 in Cell and Matrix Therapy That Improves Perfusion, Viability and Function of Infarcted Myocardium. Biomaterials, 35, 4749-4758. https://doi.org/10.1016/j.biomaterials.2014.02.028

[123] Badylak, S.F. and Gilbert, T.W. (2008) Immune Response to Biologic Scaffold Materials. Seminars in Immunology, 20, 109-116.

https://doi.org/10.1016/j.smim.2007.11.003

[124] McLaughlin, S., McNeill, B., Podrebarac, J., Hosoyama, K., Sedlakova, V., Cron, G., et al. (2019) Injectable Human Recombinant Collagen Matrices Limit Adverse Remodeling and Improve Cardiac Function after Myocardial Infarction. Nature Communications, 10, 4866. https://doi.org/10.1038/s41467-019-12748-8

[125] Zimmermann, W.H., Didie, M., Doker, S., Melnychenko, I., Naito, H., Rogge, C., et al. (2006) Heart Muscle Engineering: An Update on Cardiac Muscle Replacement Therapy. Cardiovascular Research, 71, 419-429. https://doi.org/10.1016/j.cardiores.2006.03.023

[126] Zimmermann, W.H., Melnychenko, I., Wasmeier, G., Didie, M., Naito, H., Nixdorff, U., et al. (2006) Engineered Heart Tissue Grafts Improve Systolic and Diastolic Function in Infarcted Rat Hearts. Nature Medicine, 12, 452-458. https://doi.org/10.1038/nm1394

[127] Weinberger, F., Breckwoldt, K., Pecha, S., Kelly, A., Geertz, B., Starbatty, J., et al. (2016) Cardiac Repair in Guinea Pigs with Human Engineered Heart Tissue from Induced Pluripotent Stem Cells. Science Translational Medicine, 8, $363 \mathrm{ra} 148$. https://doi.org/10.1126/scitranslmed.aaf8781

[128] Menasche, P., Vanneaux, V., Hagege, A., Bel, A., Cholley, B., Cacciapuoti, I., et al. (2015) Human Embryonic Stem Cell-Derived Cardiac Progenitors for Severe Heart Failure Treatment: First Clinical Case Report. European Heart Journal, 36, 2011-2017. https://doi.org/10.1093/eurheartj/ehv189

[129] Vela, D. and Buja, L.M. (2008) Quest for the Cardiovascular Holy Grail: Mammalian Myocardial Regeneration. Cardiovascular Pathology, 17, 1-5. https://doi.org/10.1016/j.carpath.2007.05.001

[130] Suzuki, K., Murtuza, B., Beauchamp, J.R., Brand, N.J., Barton, P.J., Varela-Carver, A., et al. (2004) Role of Interleukin-1beta in Acute Inflammation and Graft Death after Cell Transplantation to the Heart. Circulation, 110, II219-II224. https://doi.org/10.1161/01.CIR.0000138388.55416.06

[131] Lai, R.C., Chen, T.S. and Lim, S.K. (2011) Mesenchymal Stem Cell Exosome: A Novel Stem Cell-Based Therapy for Cardiovascular Disease. Regenerative Medicine, 6, 481-492. https://doi.org/10.2217/rme.11.35

[132] Wang, Z., Su, X., Ashraf, M., Kim, I.M., Weintraub, N.L., Jiang, M., et al. (2018) Regenerative Therapy for Cardiomyopathies. Journal of Cardiovascular Translational Research, 11, 357-365. https://doi.org/10.1007/s12265-018-9807-Z

[133] Yoon, Y.S., Park, J.S., Tkebuchava, T., Luedeman, C. and Losordo, D.W. (2004) 
Unexpected Severe Calcification after Transplantation of Bone Marrow Cells in Acute Myocardial Infarction. Circulation, 109, 3154-3157. https://doi.org/10.1161/01.CIR.0000134696.08436.65

[134] Sanganalmath, S.K. and Bolli, R. (2013) Cell Therapy for Heart Failure: A Comprehensive Overview of Experimental and Clinical Studies, Current Challenges, and Future Directions. Circulation Research, 113, 810-834.

https://doi.org/10.1161/CIRCRESAHA.113.300219

[135] Buja, L.M. (2019) Cardiac Repair and the Putative Role of Stem Cells. Journal of Molecular and Cellular Cardiology, 128, 96-104. https://doi.org/10.1016/j.yjmcc.2019.01.022

[136] El Harane, N., Kervadec, A., Bellamy, V., Pidial, L., Neametalla, H.J., Perier, M.C., et al. (2018) Acellular Therapeutic Approach for Heart Failure: In Vitro Production of Extracellular Vesicles from Human Cardiovascular Progenitors. European Heart Journal, 39, 1835-1847. https://doi.org/10.1093/eurheartj/ehy012

[137] Eschenhagen, T., Bolli, R., Braun, T., Field, L.J., Fleischmann, B.K., Frisen, J., et al. (2017) Cardiomyocyte Regeneration: A Consensus Statement. Circulation, 136, 680-686. https://doi.org/10.1161/CIRCULATIONAHA.117.029343

[138] Ashur, C. and Frishman, W.H. (2018) Cardiosphere-Derived Cells and Ischemic Heart Failure. Cardiology in Review, 26, 8-21.

https://doi.org/10.1097/CRD.0000000000000173 